\title{
Juventud y percepciones de la crisis: precarización laboral, clases medias y nueva politica
}

\author{
Youth and perceptions on the crisis: precarization of labour, \\ middle clases and new politics
}

\author{
Luis Enrique Alonso \\ Universidad Autónoma de Madrid \\ luis.alonso@uam.es (ESPAÑA) \\ Carlos Jesús Fernández Rodríguez \\ Universidad Autónoma de Madrid) \\ carlos.fernandez@uam.es. (ESPAÑA) \\ RAFAEl IbáÑEZ Rojo \\ Universidad Autónoma de Madrid \\ rafael.ibanez@uam.es (ESPAÑA)
}

Recibido: 29.08 .2016

Aceptado: 07.05.2017

\section{RESUMEN}

Uno de los colectivos más afectados por la crisis económica, los recortes sociales y la desigualdad creciente en los últimos años ha sido, sin duda, el de los jóvenes, que se enfrentan a un paisaje marcado por un elevado desempleo y una enorme incertidumbre vital. Como grupo vulnerable, es de enorme interés sociológico conocer cómo perciben estos cambios sociales, políticos y económicos y qué papel asignan al Estado del Bienestar en el modelo de austeridad económica vigente en Europa en este momento. Para ello, hemos desarrollado un análisis de carácter cualitativo (análisis sociológico de discursos) a partir de un material empírico obtenido de seis grupos de discusión celebrados a mediados de 2015, que habían sido organizados con el fin de analizar temas relacionados con problemas de los jóvenes españoles en su vida cotidiana. Los grupos se dividieron entre precarios jóvenes y jóvenes adultos con diferentes orígenes sociales, trayectorias personales y educativas y distintas cargas familiares, y se realizaron en la Comunidad de Madrid. El objetivo ha sido el de conocer mejor sus percepciones en relación al presente y sus expectativas sobre sus trayectorias futuras, con 
referencia a las transformaciones recientes del mercado de trabajo, los consumos públicos y sus perspectivas sociopolíticas del futuro. En este artículo se analizan los principales resultados obtenidos, a la vez que se establece una comparación con los resultados de otra investigación análoga realizada con grupos de jóvenes a mediados de 2011, con el fin de observar las variaciones en las representaciones sociales de los jóvenes a lo largo de este período y su visión del papel de los consumos públicos en el bienestar de la sociedad española. Los datos muestran un consenso llamativo entre los participantes en torno al empeoramiento de las condiciones de vida, el bienestar social y las expectativas de futuro, a la vez que un interés mucho mayor en la política.

\title{
PALABRAS CLAVE
}

Juventud, consumos públicos, precariedad, crisis económica, participación política.

\begin{abstract}
Young people in Spain have been one of the groups most affected by the economic crisis, social cuts and growing inequality in recent years. They are facing a scenario marked by high levels of unemployment and a dramatic uncertainty in their life project. Being a vulnerable group, it is of enormous sociological interest to understand not only how they perceive the recent social, political and economic changes in the country, but also to know their views on the welfare state and its role inside the current model of economic austerity that prevails in Europe nowadays. To do so, we have developed a qualitative analysis (sociological discourse analysis) drawing on empirical data obtained from six focus groups held in mid-2015 in the region of Madrid. The groups had been organized in order to discuss different issues related to the lifestyles of young Spaniards, and the participants were grouped according to different social, personal and educational profiles and backgrounds. Our goal was to achieve a better understanding of their perceptions regarding the current socio-political situation, their expectations about their future, while dealing with issues such as the most recent changes in the labour market or public consumption. In this article we present our analysis, while also comparing the results with a similar focus groupbased research conducted in mid-2011. Our aim is to identify possible changes in the social representations of young people during this period, highlighting particularly the role public consumption is considered to play in Spanish society. Data shows a striking consensus among participants regarding the worsening of life conditions, social welfare and expectations about the future, while at the same time there is a growing interest in politics.
\end{abstract}




\section{KEY WORDS}

Youth, public consumption, precariousness, economic crisis, political participation

\section{JUVENTUD Y PERCEPCIONES DE LA CRISIS: PRECARIZACIÓN LABORAL, CLASES MEDIAS Y NUEVA POLÍTICA.}

“La sociedad siempre es 'como lo menos malo'. Es que nos estamos acostumbrando a quedarnos con lo menos malo. ¿Yo por qué yo me tengo que quedar con lo menos malo, si yo lo que quiero es lo bueno?... (GD2)

"Miembros de un grupo de discusión se identificaron como de "clase media'; otro opto por la 'clase trabajadora'. Sus orígenes, trabajos e ingresos eran casi los mismos. La diferencia residía en que los que se consideraban de "clase media' estaban intentando distanciarse de una identidad poco apreciable a favor de otra con una imagen asombrosamente positiva"

Owen Jones (2012: 325)

\section{INTRODUCCIÓN ${ }^{1}$}

España lleva experimentado una situación de profunda crisis económica desde hace ya casi una década, como resultado de la gran crisis financiera y el pinchazo de la burbuja inmobiliaria que había contribuido al "milagro español". Tras unas tímidas medidas de inspiración keynesiana, desde 2010 se produjo un giro neoliberal en la respuesta a la crisis que continúa en la actualidad, y que daba prioridad total, en el caso de España, al pago de la deuda pública y la reducción del déficit público (disparados debido al costoso rescate de parte del sector financiero en el período 2010-2012) ante la presión de las autoridades europeas. Los distintos gobiernos y administraciones autonómicas y locales han asumido desde entonces, bajo la tutela de la Comisión Europea y el BCE, la puesta en práctica de drásticas políticas de austeridad, cuyo resultado más visible han sido fuertes recortes en las prestaciones y servicios sociales. Esto ha tenido un impacto indudable en la sociedad española que, de acuerdo a distintas fuentes estadísticas y bibliográficas (ver FOESSA, 2014; Colectivo IOÉ, 2015), se ha ido convirtiendo en un país cada vez más desigual en términos económicos y sociales. Esta situación ha generado un importante malestar ciudadano, que ha tenido su reflejo tanto en la calle (con numerosas protestas y manifestaciones, y con el surgimiento tanto del 15-M como de las denominadas "mareas"; ver

\footnotetext{
${ }^{1}$ Este artículo forma parte de los resultados el proyecto de investigación "Marcos sociales del nuevo mundo económico y empresarial: de la producción al consumo (MSEE)" financiado por la Universidad Autónoma de Madrid. Una versión previa fue presentada en el Comité de Investigación de Sociología del Consumo, en el marco del XII Congreso Español de Sociología, celebrado en Gijón en junio-julio de 2016.
} 
Alonso, 2014; Fernández Rodríguez e Ibáñez Rojo, 2015) como en el escenario político (con la crisis del bipartidismo y el ascenso de nuevas opciones políticas críticas, como el partido político Podemos, tercera fuerza parlamentaria en las elecciones generales de diciembre de 2015, cuya posición se ha mantenido, con una sensible pérdida de votos, en las elecciones del 26J de 2016).

Uno de los colectivos más afectados por la crisis ha sido, sin duda, el de los jóvenes, que se enfrentan a un panorama como mínimo poco halagüeño: el desempleo, el más elevado de Europa junto al de Grecia, y una situación de gran incertidumbre. No es que no fuera un colectivo en riesgo anteriormente, como habían mostrado diversos estudios a lo largo de las últimas décadas (ver como ejemplo Santos Ortega, 2003); no obstante, su situación se ha deteriorado notablemente en los últimos años, al aumentar su tasa de paro hasta niveles dramáticos y sufrir importantes recortes en materias socialmente tan sensibles como la educación o las ayudas a la vivienda. Como colectivo vulnerable que es, tiene enorme interés sociológico conocer cómo este grupo social está percibiendo los cambios sociales, políticos y económicos que están teniendo lugar, y qué papel asignan los jóvenes al Estado del Bienestar en el modelo de austeridad económica hegemónico en Europa. En este artículo, se presentarán y discutirán los resultados obtenidos del primer análisis en torno a los temas fundamentales que definieron el discurso de los grupos en torno a la situación social y política.

\section{PLANTEAMIENTO Y DISEÑO DE LA INVESTIGACIÓN}

Los participantes en los grupos de discusión que habíamos celebrado en el año 2011 (ver Alonso, Fernández Rodríguez e Ibáñez Rojo, 2012) habían coincidido en expresar un enorme malestar con su situación personal, articulando un discurso muy desesperanzado, con una imagen del futuro teñida de incertidumbre en el que los riesgos parecían ser mayores que las esperanzas u oportunidades. En nuestro análisis, habíamos reflexionado sobre el nihilismo de la juventud del momento, en una situación de profunda crisis económica en la que las narrativas de la crisis todavía enfatizaban el discurso del "hemos vivido por encima de nuestras posibilidades" hegemónico en ese momento (Alonso, Fernández Rodríguez e Ibáñez Rojo, 2011 y 2014) y previo a la eclosión de un discurso más crítico influido por el 15-M y las mareas (Alonso, Fernández Rodríguez e Ibáñez Rojo, 2016a). Entre los jóvenes que participaron en aquellos grupos de discusión, la percepción dominante era la de una frustración extraordinaria ante la asunción (teñida de un enorme fatalismo) de la precariedad como condición vital y la imposibilidad no ya de acceder al mismo nivel de vida que sus progenitores, sino de desarrollar un proyecto vital con cierta autonomía a medio plazo ${ }^{2}$. Sin embargo, la reacción frente a esta situación era una aceptación

${ }^{2}$ Los resultados de aquella investigación situaban la precariedad como algo que iba mucho más allá de una simple condición de inestabilidad en el mercado de trabajo sino como una 
pasiva del sistema, refugiándose en el consumo y el disfrute de experiencias como espacio de goce frente a las dificultades de inserción en un mercado laboral balcanizado y precarizado, y aspirando, a largo plazo, a una mejora económica que les permitiera, al menos a la mayoría de los participantes, aspirar al viejo sueño del desarrollismo español de tener una vivienda en propiedad, pero manteniendo además hábitos de ocio y consumo post-adolescentes, los únicos con legitimación social una vez que el relato hegemónico de las sociedades liberales de mercado (la autonomía y la progresión profesional) es cada más difícil de enunciar en estas circunstancias. El consumo, o mejor dicho el hiperconsumo, creaba así el marco de referencia de la inclusión social, aunque era generalizada la percepción de que la vulnerabilidad social estaba ahí, acechándoles, y que su deseo de crecer profesionalmente y construir una existencia autónoma se estaba sosteniendo sobre pilares muy frágiles.

Cuatro años después, y teniendo en cuenta los muchos acontecimientos que han tenido lugar en España en este período (una nueva legislatura marcada por los recortes y el aumento de las desigualdades, el rescate parcial al sistema financiero, los escándalos de corrupción, los movimientos de protesta, la aparición de nuevos partidos políticos), hemos considerado que era muy importante prestar atención de nuevo a las percepciones de los jóvenes, sobre todo una vez que los resultados obtenidos en nuestros análisis de otros grupos sociales había mostrado un cambio en las actitudes de la ciudadanía, la cual había pasado de la culpabilidad y la angustia a la indignación (ver Alonso, Fernández Rodríguez e Ibáñez Rojo, 2016a y 2016b). Pensamos que la mejor estrategia de diseño era la de intentar replicar el mismo análisis cualitativo (análisis sociológico de discursos), sobre una muestra cualitativa de grupos estructurada con la mismas características que el diseño original, aunque por restricciones presupuestarias el trabajo de campo se realizó sólo en la Comunidad de Madrid. Este consistió en seis grupos de discusión celebrados en junio y julio de 2015, organizados con el fin de analizar temas relacionados con problemas de los jóvenes españoles en su vida cotidiana y su visión del contexto político y social del momento. Los grupos se dividieron, tal y como se había hecho en 2011, entre precarios jóvenes y jóvenes adultos con diferentes orígenes sociales, trayectorias personales y educativas y distintas cargas familiares. En el diseño de la muestra se ha tratado de considerar, junto al eje del estatus socioeconómico, un eje (horizontal) que presupone una tipología de orientaciones ideológicas respecto a la construcción de la ciudadanía. Se trata obviamente de un diseño intencional que busca saturar el espacio discursivo que discurre entre las posiciones más defensivas y particularistas y las posiciones más politizadas y capaces de proponer un discurso universalista e integrador. Sin duda este eje es muy dependiente de la composición concreta de los grupos

condición radical que se incrustaba como precariedad vital en los estilos de vida, el horizonte de expectativas y los imaginarios (a) políticos de los jóvenes cosa que se mostraba sistemáticamente y de manera más amplia en los trabajos presentados por Benjamín Tejerina recogiendo diferentes ámbitos de la vida social española y francesa (véase Tejerina et al. 2013) 
y puede no ser adecuadamente representado por las mayorías hegemónicas de algunos perfiles ${ }^{3}$. El gráfico muestra la composición de cada uno de esos grupos:

\section{Gráfico 1: Composición de los grupos de discusión:}

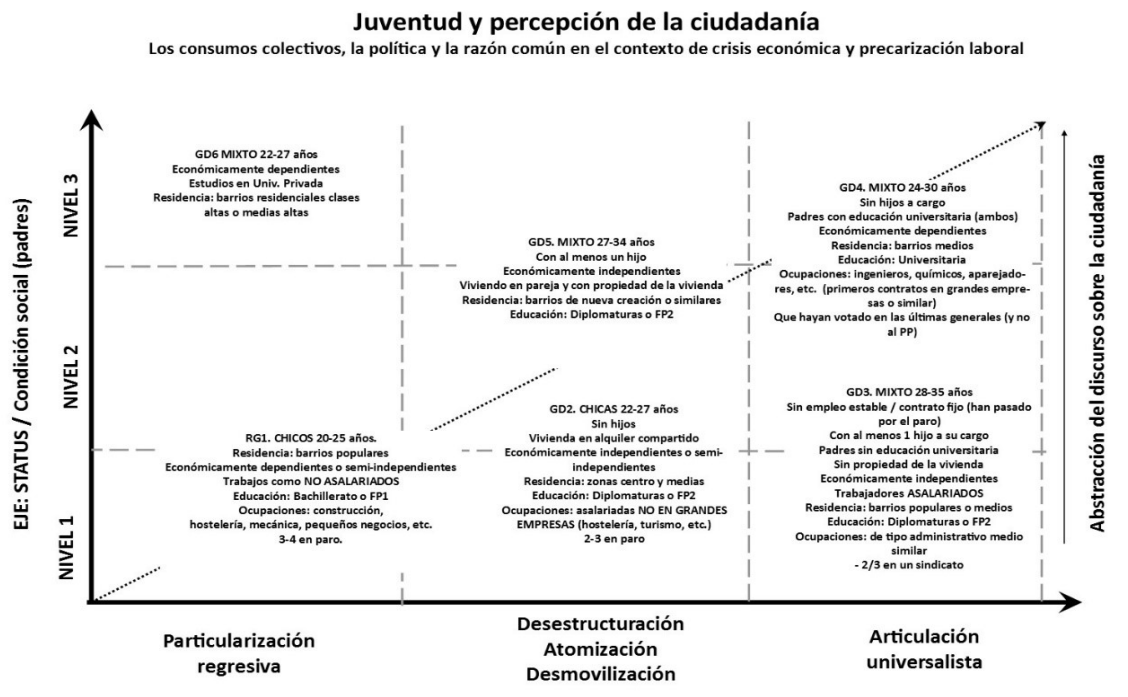

El objetivo principal era conocer mejor las percepciones juveniles en relación al presente y a sus potenciales trayectorias futuras, con referencia a las transformaciones recientes del mercado de trabajo, los consumos públicos y sus perspectivas de cambio. Con ello se trataba de realizar un estudio con una cierta perspectiva longitudinal-diacrónica y con posibilidades comparativas en el tiempo, cosa que habitualmente no abunda en los enfoques cualitativos donde suele primar el estudio instantáneo, ya sea etnográfico o estructural (Flick, 2015: 70-71). Sin embargo, las propias circunstancias concretas obligaban a ciertas modificaciones en el guión y las provocaciones utilizadas en las dinámicas, por lo que la comparación con respecto a los discursos de 2011 es necesariamente indirecta. Tras más de cinco años de crisis, la provocación inicial de las

${ }^{3}$ Por ello, este eje tan sólo es utilizado de forma implícita en nuestro análisis posterior. Y no puede ser de otra manera, dado que dentro de cada grupo aparecen fracciones que se sitúan en posiciones ideológicas o bien diferentes de las esperadas por los investigadores, o bien diferentes a las de la fracción hegemónica de su propio grupo. Por ello, una determinada posición, por ejemplo la crítica a las nuevas formas de segmentación que estaría generando la política educativa, puede estar representada por participantes de un perfil que en nuestro diseño no representaría de forma central esa posición (algo que de hecho ocurrió con frecuencia en el grupo RG1, más progresivo y politizado de lo esperado en nuestro diseño). 
reuniones giró en torno a si estaba teniendo ya lugar una salida paulatina de la situación de crisis, en lugar de una pregunta más directa sobre los cambios en hábitos de vida y de consumo provocados por la crisis (tal y como se hizo en las reuniones de 2011). Por otra parte, en torno a la gestión concreta de la crisis apenas podía haber discurso en 2011 y era, por el contrario, central cuatro años después. Finalmente, la emergencia de nuevas alternativas políticas y la reciente celebración de las elecciones locales (con resultados especialmente significativos en Madrid) también modificaba necesariamente la orientación temática de los grupos respecto a unos años atrás. En este sentido, el análisis que realizamos no respeta la misma dinámica y el mismo guión utilizado en los grupos de 2011, por lo que el análisis comparativo no busca una sistematicidad formal; más bien trata de utilizar, por analogía la referencia de los grupos realizados hace cuatro años para captar parte del movimiento que ha tenido lugar en el espacio ideológico de los discursos en torno a la crisis.

Los grupos se condujeron y analizaron siguiendo las directrices marcadas por la conocida como Escuela Cualitativa de Madrid (especialmente utilizados aquí han sido los trabajos de Ibáñez (2015); Ortí (1986); Gutiérrez Brito (2008) y Conde Gutiérrez del Álamo (2009)), apostando particularmente por un análisis de carácter sociohermenéutico (Alonso, 2013). De este modo, no hemos realizado un análisis cuantitativo del contenido textual de los grupos, ni una interpretación psicoanalítica de sus subculturas de referencia, tampoco hemos tratado de hallar invariantes lingüísticas en forma de estructuras subyacentes de los enunciados producidos por los grupos. De las posibles formas de hacer un análisis del discurso en ciencias sociales (Íñiguez Rueda, 2003), hemos apostado por un estilo específico de análisis posible de los discursos en sociología, como una sociohermenéutica ligada, fundamentalmente, a la situación y a la contextualización histórica de la enunciación, en tanto que interpretación ligada a la fuerza social y a los espacios comunicativos concretos que arman y enmarcan los discursos. Hemos tratado de realizar, por tanto, la reconstrucción del sentido de los discursos y de los significados que le dan a su situación -micro y macrosocial- los actores implicados en la investigación. De esta forma, no hemos practicado un análisis formalista, sino fundamentalmente hermenéutico (Beltrán 2016), guiado por la fenomenología, la etnología y la teoría crítica de la sociedad, tratando de encontrar los ejes principales de representación, significación y de comprensión de estos textos concretos en su contexto social y en la historicidad de sus planteamientos, desde la reconstrucción de las prácticas sociales de los actores que están implicados en el discurso (Fairclough, 2003:2139).

Siguiendo a Fernando Conde (2009; 2015:641-663) hemos realizado nuestro trabajo de lectura del material textual producido, como un análisis de las "configuraciones narrativas", lo que significa generar una aproximación literal y global del corpus de textos en función de los objetivos de la investigación, de tal manera que seamos capaces de construir un modelo de interpretación generado sobre aquellos vectores multidimensionales de los textos que cumplan -según el propio Conde- con dos condiciones: a) que tengan capacidad de 
ordenar la totalidad de los mismos, desde el punto de vista interno de los textos, de su grado de articulación temática y de su consistencia interna a la luz de la dimensión elegida; b) que tengan capacidad de conectar el sentido general del texto con el contexto concreto de producción del mismo y con los objetivos de la investigación. El análisis de la "configuración narrativa", pues, consiste en elegir y seleccionar aquellas dimensiones del texto que dando cuenta literal del mismo, permiten, al mismo tiempo, polarizarlo y ponerlo en relación tanto con el contexto social en el que se ha producido como con los objetivos de la investigación. Así, el análisis de la "configuración narrativa" del texto producido por un grupo consiste en descubrir y aislar el conjunto de tensiones discursivas o ejes temáticos, y campos semánticos, de los textos que operan a modo de hilos que tejen la trama de la dinámica grupal. Para encontrar las citadas dimensiones que organizan la trama que sostiene y, al mismo tiempo, se expresa en los textos, hemos tratado de encontrar y radicalizar las tensiones, los conflictos, las diferencias de posiciones y de opiniones que se expresan en los grupos. Posiciones que se configuran como los polos de un campo de fuerzas que construye, en lo fundamental, el conjunto de debates mantenidos en los grupos y que se expresan en los textos de las trascripciones. Por todo ello, la construcción de la "configuración narrativa" del texto es una operación prácticamente inversa a la de la "categorización analítica". En lugar de descomponer el texto, se trata de ver las fuerzas que lo mantienen en la generalidad de la enunciación.

Concretamente el análisis sociológico de los discursos de este artículo se dividirá en tres secciones dedicadas a explorar, por tanto, los ejes temáticos -y los campos semánticos- en parte construidos y en parte provocados en las discusiones de grupo, y que se encuentran de forma más o menos explícita en los textos de las transcripciones.. La primera de dichas secciones se centrará en las percepciones de los jóvenes en torno a su situación personal, su proyecto vital y sus expectativas de futuro. La segunda examinará la visión de los jóvenes en torno a los consumos públicos y el Estado del Bienestar, en la que se hará hincapié en la reflexión en torno a la situación del significante "clase media" en este momento, continuando con una reflexión desarrollada con antelación (ver Alonso, Fernández Rodríguez e Ibáñez Rojo, 2016a y 2016b). El tercer bloque se centrará, finalmente, en su visión del posible cambio político que estaba / está experimentando el país (de alguna manera muy presente en el momento en que se realizaron los grupos, junio/julio de 2015, poco después de las elecciones municipales y autonómicas que llevaron a la alcaldía al equipo de Ahora Madrid), dedicándose el último bloque a un apartado de conclusiones. Estos tres ejes temáticos tratan de respetar el propio desarrollo de las dinámicas, en parte construido por el guión de las reuniones y en parte por la propia espontaneidad de las dinámicas más productivas. 


\section{PERCEPCIONES SOBRE LA SALIDA DE LA CRISIS Y EXPECTATIVAS DE FUTURO}

Dentro de una tónica aparentemente no muy diferente de la que tenía lugar en 2011, todos los grupos arrancan la dinámica de las reuniones con un conjunto de experiencias directas o indirectas sobre la pésima evolución del mercado de trabajo y las condiciones de trabajo en general. Sin embargo, habiendo sido preguntados ahora sobre su valoración de los argumentos en torno a la salida progresiva de la crisis en la que ya habría entrado la economía española, apenas hay alguna posición minoritaria que acepta ese diagnóstico. Casi sin excepciones, los participantes en los grupos señalan que no han tenido lugar mejoras significativas. Y aunque hacen suyas las descripciones mediáticas sobre la mejoras en las cifras macroeconómicas, y en algunos casos sí señalan experiencias positivas en la mayor facilidad para encontrar empleo, todos los diagnósticos positivos quedan inmediatamente eclipsados por un consenso prácticamente absoluto en torno a la reducción global de los salarios y el empeoramiento de las condiciones de trabajo 4 que ha tenido lugar a lo largo de la crisis. Esta situación no parece estar cambiando en esta última fase de relativa mejora económica. Incluso en los grupos centrales (como el GD5 ${ }^{56}$ ) se suceden las intervenciones recopilando todo un conjunto de experiencias de trabajo precario, ilegal, a comisión, etc. Describiendo la sensación de enfrentarse a un mercado de trabajo radicalmente distinto de aquél para el que se habían preparado:

Sí, es como si hubieran cambiado las reglas del juego y nos hemos quedado un poco "¿ahora qué hacemos?". Y no sabemos bien qué hacer, porque, claro, al final te tienes que agarrar a lo que sea. (GD5)

${ }^{4}$ Esta parte del análisis trata de continuar los análisis que se realizaron con grupos de jóvenes en los años iniciales de la crisis y que se recogen como hemos dicho en Alonso, Fernández Rodríguez, e Ibáñez Rojo, (2012). Evidentemente la idea de pérdida de calidad en el empleo y de devaluación salarial continuada a lo largo de este último periodo sigue siendo el referente de los discursos, degradación y devaluación que por otra parte es bastante evidente que se puede mostrar fácticamente siguiendo los datos de empleo, la evolución salarial y los cambios jurídicos de (des) regulación del mercado de trabajo, tal como ha hecho con contundencia el economista José Ignacio Pérez Infante (2015 y 2016). Por lo tanto el proceso de paradójica construcción de la juventud por el mercado de trabajo -como lo denomino en su día Amparo Serrano Pascual (1995)-, que a la vez que demanda identidades de adulto sigue manteniendo en una posición dependiente, subordinada y radicalmente insegura a grandes franjas de la población juvenil, sigue estando absolutamente presente como situación y como percepción por lo que la idea de precariedad y sus derivados sigue siendo nodal e indisoluble con cualquier acercamiento a la vida de las diferentes trayectorias juveniles, tal como han teorizado Jones (2012), Cingolani (2015) o Standing (2013y 2014).

5 GD es la abreviatura que utilizamos en este trabajo para referirnos a "grupo de discusión". En los fragmentos seleccionados, "H" representa "Hombre" y "M", "mujer", si bien solamente se ha indicado en aquellos casos en los que aportaba alguna información pertinente. Lo que no se ha considerado necesario para los fragmentos seleccionados a lo largo de este trabajo es la identificación individualizada de los participantes.

${ }^{6}$ GD5 representa nuestro grupo central desde el punto de vista del diseño muestral, ubicado en posiciones sociales intermedias y más indefinido y heterogéneo ideológicamente. 
Respecto a los grupos de 2011, la primera fase de las dinámicas de los grupos refleja un discurso algo más depresivo, pero no hay cambios muy significativos, más allá de la mayor rotundidad con la que se expresan experiencias personales (fundamentalmente laborales) más o menos extremas derivadas de la crisis. Pero la construcción por los grupos de la base del espacio discursivo es relativamente similar. Lo más llamativo es la narración que en todos los grupos (quizá con la excepción del grupo con perfil más acomodado de estudiantes de universidad privada, GD6) presenta con cierta contundencia las estrategias de supervivencia laboral por las que han ido necesariamente transitando, debido al contexto tan negativo con el que se han encontrado en el momento de su inserción en el mercado de trabajo. Incluso los jóvenes universitarios de nuestra GD4 (representantes de los hijos de las clases medias funcionales) son muy conscientes de una degradación significativa del tipo de trabajo al que puede aspirarse en el contexto actual:

"Vale sí, te sacan puestos de trabajo, sí, ¿pero de qué calidad?, ¿qué calidad? O sea, estamos saliendo de una crisis..., de una crisis que ellos consideraron que era la crisis importante y nos estamos metiendo en otra crisis mucho peor, una crisis de..., una crisis laboral, una crisis familiar... terrible." (GD4)

Este mismo grupo expresa cómo se ha tomado conciencia de la pérdida de poder adquisitivo que ha tenido lugar a lo largo de estos años de crisis. Incluso resulta muy significativo cómo se presenta la figura del mileurista como un privilegiado:

"Si te lo planteas, si te lo planteas realmente, hace cinco años estos debates eran porque nos echábamos las manos a la cabeza porque: «nuestros jóvenes son mileuristas"». Y era: «Dios mío, España se va a la mierda porque no podemos tener una España de mileuristas». Y ahora mil euros es el animal mitológico favorito, o sea... (RISAS), no existe. Y no existe porque nos hemos acostumbrado..., bueno, nos hemos acostumbrado y nos han acostumbrado." (GD4)

Ese cambio en las reglas de juego, es simultáneamente un cambio en los términos de la negociación. Como muy bien refleja una de las participantes en el grupo de jóvenes de nuestro GD2, la presión de los últimos años ha conseguido ir moviendo hacia abajo la capacidad de resistencia. Incluso a pesar de las denuncias constantes, de las situaciones más sangrantes casi de esclavización, de salarios por hora indignantes, etc., lo cierto es que, a su manera, los grupos recogen el abaratamiento del coste de la mano de obra en España que ha tenido lugar durante la crisis:

"o sea, quizás estamos...,¿no? Esta sensación de que parece que estamos saliendo. Estamos saliendo aposta de que nos hemos...hemos bajado el nivel de conformismo, ¿no? Nos conformamos con menos. O sea, se podría decir... imagínate que dijésemos todos: "Sí, estamos saliendo. Vale. ¿Por qué? Porque aceptamos trabajos de mierda, porque vendemos nuestras casas a precios de 
mierda, porque cobramos menos, ¿no? Imagínate, exagerado. ¿Qué estamos saliendo de la crisis? No..." (GD2)

La crisis se ha prolongado durante tantos años que los jóvenes de más edad (28-35 años en nuestro GD3) casi plantean el cambio como una cuestión generacional. Este efecto del largo recorrido de desencantos provocado por la prolongación indefinida de la crisis construye un nuevo temor ausente en las reuniones de 2011. Dentro del relativo giro ideológico que ha tenido lugar estos años (especialmente entre una parte de los jóvenes), mientras en 2011 algunos grupos hablaban despectivamente de los nini elaborando un discurso culpabilizador; en 2015, por el contrario, en varios momentos y en diferentes grupos se justifica como un producto de la crisis la falta absoluta de motivación entre los jóvenes para construir sus trayectorias formativas. De esta forma, desde la perspectiva de estos jóvenes mayores del GD3, ha tenido ya lugar un salto generacional en el interior de la crisis, y "encima lo que viene por detrás nuestro... formativamente está peor" (GD3). En este grupo GD3, el de perfil más crítico y con algunos participantes implicados en asociaciones y colectivos de barrio, el cambio se plantea como una ruptura histórica:

“¿Pero te das cuenta que hemos vuelto como cincuenta años atrás, que cada uno se busca la vida como podía? Nos falta coger el saco de patatas y ponernos en la carretera." (GD3)

Pese a la falta de motivación, resulta igualmente obvio que no queda otro camino que la lucha competitiva por una formación constante ya que el que se frena en la carrera se queda inmediatamente en la cuneta:

"No, y mantienen corriendo, porque terminas el curso y ya luego te exigen otra cosa, primero era inglés, ahora es mandarín, (RISAS) luego van a pedir quién sabe qué. Y cuando termines ya... sí, un idioma, te piden otro. (- Madre mía... уо...) Y te mantienen corriendo, corriendo, corriendo... (- A mí es que me da una pereza ya, lo de hacer cursos...) Y para un trabajo como ese a ver, como antes lo hacía igual." (GD3)

Desde la posición más cómoda desde la que participan en esta carrera los miembros del grupo GD4, la necesidad de una adaptación permanente y de la "empleabilidad" está totalmente asumida. Sin embargo, esta idea de un cambio en las reglas de juego, de una incertidumbre que rompe con cualquier posible estrategia racional para insertarse en el mercado de trabajo, es planteada en estos términos planificados sólo por los perfiles más acomodados. Ya no se trata sólo de una dificultad mayor o un tiempo más prolongado para alcanzar un trabajo digno, es más bien la descripción de una arbitrariedad y de un cierto caos dentro del que es muy difícil desenvolverse:

"Lo de la adaptabilidad del mercado, que (...) de moda: "no, no, es que hay que ser totalmen..., hay que ser adaptable a lo que pide el mercado...". A lo mejor el problema es que no..., tampoco es tan claro lo que pide el mercado (SE RÍE)... O sea, el sentimiento ese de decir: "Dios mío, nunca..., nunca..., doy un perfil de lo que pide el mercado" (GD4) 
Dentro del grupo de origen social más elevado (GD6), tampoco se cuestiona en ningún momento el empeoramiento radical de las condiciones de trabajo que ha tenido lugar durante la crisis. A través de "jornadas de trabajo terribles" en condiciones que "han empeorado muchísimo" describen una degradación de la situación del mercado de trabajo que es para ellos -en contraste con el resto de grupos- el resultado de un aumento de la competencia y, en particular, del excesivo número de universitarios. Por ello, es la única dinámica en la que aparece una posición que asume la crisis como un castigo necesario, como una forma de "despertar" del letargo para un país retrasado:

"Y ahora nos toca a nosotros otra vez. Pero yo creo que nos... nos puede venir bien porque esta juventud que ahora se tiene que ir fuera, va a abrir su mente mucho y va a conocer mucho que... que es lo que le falta a España: abrir un poco la mente porque yo veo que la gente es muy muy cerrada, muy cuadriculada, las ideas. Si nos vamos a la política, siguen habiendo peleas entre izquierdas y derechas. Así nunca vamos a ir. Y la gente no se da cuenta, se sigue peleando por estupideces, cada vez más cerrados, más cerrados. Entonces, la gente que se vaya fuera y que venga dentro de unos años, va a venir con ideas nuevas, con... con nuevas experiencias que, seguramente, ayude al país a mejorar" (GD6)

El extremo opuesto, y en muchos sentidos la vivencia más dura, la expresan los jóvenes de nuestro GD1. Hijos de las clases populares, herederos de la deuda moral que implican los sacrificios de sus padres para sacar las familias adelante, traducen el largo camino de la crisis en una presión ética que nace de la vergüienza por no poder contribuir a la economía familiar: "Sí, que te da apuro hablar con tus padres, decir «déjame dinero», porque tampoco lo tiene" (GD1). Para ellos el hecho de tener que prolongar los estudios tiene un coste específico, pues en muchos casos, más que una muestra de esfuerzo y de disciplina, es expresión de una impotencia:

“- Y mi padre quiere que me independice, que me independice, pero es muy difícil...

$[\ldots]$

- Te sientes mal. A mí...un poco vergonzoso, la verdad. De decir: «tengo 23 años, no puedo colaborar en casa, tampoco me puedo ir de casa». Entonces...no, está mal hecho... Y quieres estudiar, y tiene que pagar tu madre. Si no te lo puede pagar, te jodes y no estudias...” (GD1).

En coherencia con los perfiles seleccionados, son este grupo GD1, junto con el grupo GD4, quienes de forma más o menos explícita y más o menos optimista, plantean en algún momento de las dinámicas la idea de que la situación ha llegado ya a un límite. Y ha llegado a un límite de tolerancia por parte de la mayoría de la gente, situada en una posición desde la que sólo puede adoptarse una posición ofensiva o, como lo expresa uno de los participantes en el GD1, "sólo puedes tirar para adelante": 
“- Lo noto mucho. Sobre todo, en la gente más mayor. En la gente joven también, pero la gente más mayor...es que he visto toda la gente mayor que he conocido a lo largo de la crisis los he visto, poquito a poco, marchitándose. Que cada vez cargabas con más cosas, y como que... y no veían que salieran...Yo, viendo a la gente cada vez, más tal, más tal. Y parece que ahora sí están un poco...la gente está más...

(HABLAN DOS HOMBRES A LA VEZ)

(...)

- Sí, sí, ha habido un punto de ruptura...

- El fin, la muerte y han dicho: “coño, ya aquí solo puedes tirar para adelante"...

- Claro, sí, sí, sí.

- Solo puede haber mejoras." (GD1)

En la dinámica de nuestro GD4 hay un cuestionamiento más intelectual de la crisis, en torno a los engaños del supuesto poder del «mercado» y a las cuestiones que "nos han metido con calzador".

"Claro, pero yo creo que va a llegar un punto en que la gente no va a poder mantener una vida digna..., por si solos, y entonces, yo creo que..., no sé... Por ahí tiene que explotar, tiene que..., que haber alguna reacción también sobre esto, ¿sabes? Tanto como ha habido la reacción del 15M, también tiene que haber una reacción por parte del sector joven..., en el sector empleo, ¿no?” (GD4)

En el nivel más general de análisis, el cambio más significativo en las mayorías centrales de estos grupos con respecto a los grupos celebrados en 2011, es que ahora muestran los límites del discurso del miedo. Tanto en el grupo central (GD5), como en el grupo de posición más precaria (GD3), se plantean de forma explícita los límites para la eficacia de dicho discurso, por un lado porque la falta de expectativas y la situación material limita su eficacia (cuanto menos hay que perder, cuando ya todos los riesgos han sido asumidos...); y, por otro, por la existencia de un contexto ideológico más plural, en el que las alternativas posibles aparecen más abiertas dentro del actual contexto político. De diferentes maneras se recoge la idea de una pérdida histórica, de un retroceso profundo ("Por el miedo mira todo lo que hemos perdido: un montón de derechos, todo lo que nos han quitado y a ver eso cuándo se recupera", GD5), pero simultáneamente se considera que afrontamos un nuevo ciclo:

"De todas formas, los políticos de ahora, menos los nuevos, nos están enseñando lo que es el miedo, porque cada día que te levantes es: los soviets por un lado, que va a venir los... que va a volver Franco, que van a venir otra vez los rojos, que ahora... Y realmente, yo creo que en la sociedad en la que vivimos ahora, en la que la mayoría tenemos estudios de algún tipo, o no, pero tenemos algo más de educación, sobre todo que ya podemos, en este sector que tenemos de edades, vemos que ya no nos engañan realmente, que te sigan viendo esa necesidad de meternos miedo y miedo y miedo." (GD3) 
Esta relativa ineficacia del discurso del miedo es una de las singularidades del discurso de los jóvenes frente al discurso de los mayores. La construcción de una subjetividad sin ningún tipo de proyecto a medio y largo plazo ha minimizado la eficacia de los temores al cambio y al derrumbe del marco institucional surgido del acuerdo constitucional. Sin que los grupos reflejen ningún entusiasmo por los nuevos partidos y la nueva política, sí que elaboran un discurso mucho más proclive a la exigencia de un cambio, frente a los recelos del discurso dominante en los grupos de más edad.

\section{EL AUMENTO DE LA DESIGUALDAD Y EL DECLIVE DE LOS SERVICIOS PÚBLICOS}

Debido al perfil y los rangos de edad de los grupos seleccionados, hay dos grandes temas en torno a la evolución de los servicios públicos y la percepción sobre los recortes y la política de austeridad (la educación y las ayudas a la maternidad). Y hay un elemento de fondo a través del cual se definen dichos cambios: el aumento de la desigualdad y el vaciamiento, casi absoluto, del significante clase media ${ }^{7}$.

Si comenzamos el análisis por la dinámica de nuestro grupo central (GD5), las posiciones que en él emergen van a ser reproducidas con significados similares en el resto de grupos (salvo en el GD6). El elemento central del discurso en torno a los servicios públicos muestra los resultados del empobrecimiento que ha sido previamente descrito al presentar la situación del mercado de trabajo y el descenso en los salarios.

"Es que los umbrales los han bajado, es que tienes que estar muy mal, muy mal, muy mal. O sea, cuando ves que está ese tope, dices: "joder, si nosotros estamos de puta madre" (GD5)

El Estado de Bienestar actúa sobre un volumen creciente de población

${ }^{7} \mathrm{El}$ tema de la quiebra material -y sus efectos en la representaciones sociales de las diferentes trayectorias juveniles- de las clases medias herederas de la edad de oro del Estado del bienestar que sirve de eje de interpretación del material textual derivado de nuestra investigación se pone en relación directamente con otro trabajos nuestros de carácter más general realizados también siguiendo la evolución de los discursos sociales según ha ido madurando la crisis y el lugar que ha tomado la imagen de las clases medias en esta evolución; véanse Alonso, Fernández Rodríguez e Ibáñez Rojo (2016a y 2016b). Las referencias teóricas para enmarcar este asunto son Gaggi y Narduzzi (2006), Chavel (2006), Cowen (2014) y Hernández (2014). Por su parte, Peugny (2009) y Maurin (2009), al trabajar sobre las consecuencias sociales de la crisis sobre los modelos de regulación redistributivos, se centran en las formas básicas de desclasamiento, concepto que aparece constantemente como realidad fáctica o como temido fantasma en todos nuestros grupos de discusión. Paralelamente, Julien Damon (2013: 64-67) hace un completo catálogo razonado de los términos que se han atribuido en los últimos años a la evolución las clases medias europeas y norteamericanas, términos nada tranquilizantes como penalización, erosión, pulverización, desmigajamiento, fragmentación, etc., que siempre remiten a un miedo a una especie de regresión a una sociedad estamental presente también en nuestros grupos. 
marginal, y ha ido endureciendo los criterios de acceso a las ayudas hasta el punto de excluir en muchos casos a quien fuera centro privilegiado de los servicios públicos: la clase media. Ya que, por otra parte, los servicios universales (como educación y sanidad) han ido perdiendo calidad de forma sistemática según las mayorías centrales de todos los grupos. Ahora mismo, los grupos parecen compartir la percepción de que sólo la población en situación límite tiene acceso a las ayudas estatales. Una antigua clase media, empobrecida, debe seguir sintiéndose privilegiada -pese a haber perdido bienestar por la doble acción de los recortes salariales y los recortes en las prestaciones sociales-, pues la situación de crisis ha hecho emerger situaciones de pobreza extrema. Dentro de esta acelerada movilidad social descendente:

"La clase media es un poco una especie de utopía y como está el nivel ahora, ahora mismo yo sería clase baja. Por nivel de estudios, pues no sé, clase media-alta o alta, pero económica, baja." (GD5)

Las dificultades en el acceso a las ayuda se han reforzado al intensificarse la rigidez burocrática, que lejos de considerar las ayudas y prestaciones como derechos, multiplica la complejidad y las exigencias de requisitos.

“- Y aparte, yo el problema que veo, por lo menos, yo cuando solicito las becas de transporte, de estudio, libros...es que tienes que hacer un máster para...son...son...es que no te dan...entre que es complicado enterarte de cuándo son. Ya, cuando ya te has enterado, y lo vas a hacer, es "ponte a hacerlo"...

- Te ponen...te lo ponen tan difícil...

- Te lo ponen tan difícil, que es que no...

- Juegan a cansar a la gente." (GD2)

Obviamente, según se desciende en el perfil social de los grupos es más dramática la percepción de un empobrecimiento y una polarización social que se considera indiscutible. En un análisis anterior (Alonso, Fernández Rodríguez e Ibáñez Rojo, 2016a y 2016b) ya habíamos señalado cómo los discursos de los grupos compartían una descripción común sobre el crecimiento de la desigualdad y la creciente polarización social. Si ahora la clase media se ha convertido en clase baja... ¿qué es ahora la clase baja?, se pregunta uno de los participantes en nuestro GD1:

"si estamos diciendo que está bajando la clase social, pues...si...si la clase media ya ves que se baja, la clase baja ¿qué es? Es...es nada. En la calle, desahucio. Ya está, lo que está pasando, ¿sabes? Desahucias familias que toda la vida pagando, desahucias, a la calle (...)" (GD1)

Si esa creciente desigualdad ya hacía aparecer en algunos discursos las comparaciones con la estructura social que se consideraba propia de América Latina, en estos grupos de junio de 2015 es significativo que aparezcan ya los términos de "pobreza energética" o de "trabajador pobre". 
- M: Ahora nos llaman trabajadores pobres ¿no? (- M3: Sí.) Nos llaman trabajadores pobres.

- M: Sí, es verdad, es que es imposible ahorrar. (- M2: Ya.) Vamos yo tampoco lo consigo, vamos. (GD3)

En este punto, los grupos reproducen una perspectiva sobre los efectos de una desigualdad creciente que ya había aparecido en los grupos de más edad realizados unos meses antes. Y, por otra parte, magnifican la distancia ideológica respecto al discurso moralista y culpabilizador de los primeros años de la crisis. Los gastos fijos de la vivienda se han convertido en auténtica obsesión para algunas fracciones de los grupos, y son utilizados como un síntoma de una degradación sustantiva de la calidad de vida, si bien son en muchos casos presentados orgullosamente como formas de ahorro y de adaptación:

"H: A mí no me da la gana. O sea, yo tengo un niño y no enciendo la calefacción, ¿sabes cómo te digo?: manta zamorana. (Ríen varios). Es verdad, doy la calefacción solo si viene el niño a las cuatro, a las dos y media se la pongo porque, encima, su habitación es la más fría, para cuando llegue no me ponga la excusa de que hace frío para estudiar, ¿sabes?, y el hace los deberes, y la apago a las ocho. Y luego, el resto el día, con lo a gusto que se está en el sofá, en vez de una, con dos mantitas ya eso...

- M: La Tarifa Bata-manta puede ser." (GD5)

“- M: Deberían hacer una ley de esas..., ahora no me acuerdo cómo se llaman, no sé si es de gasto mínimo; no, de pobreza energética, ¿no?, que el Estado se responsabilizase de la gente que no puede pagar, o sea que no puede haber gente en enero que pase frío, es que no puede ser eso. No te digo nosotros que podemos poner la calefacción, hay gente que no la puede poner, ¿sabes?, o que está calentando...

- H: O están con velas.

- M: Efectivamente" (GD5)

En contra de lo que ocurría en los grupos de 2011, en las dinámicas de prácticamente todos los grupos de 2015, los jóvenes han renunciado de forma mayoritaria a acceder a la propiedad de la vivienda, y algunos más bien se muestran felices de haber podido escapar de la trampa que ha supuesto para una parte de su generación la firma de hipotecas durante los años del boom inmobiliario. Si bien en 2011, el grupo de posición más precaria ya había puesto sobre la mesa la emergencia una picaresca creciente para reducir los gastos cotidianos ("engancharse" a la luz, nuevas formas de consumo, etc.), ahora aparece con más normalidad en varios grupos la necesidad de ahorrar en los costes fijos de la casa, e incluso argumentos en defensa de estrategias colectivas de ahorro (como las lavanderías colectivas, tarifas de luz alternativas, etc.).

Aunque en ello incide sin duda alguna que todos los grupos fueron realizados en Madrid, lo cierto es que las experiencias de acceso a algún tipo de ayudas al alquiler o a la emancipación económica (por cualquier otra vía) son prácticamente nulas. Y en el otro gran elemento central de las prestaciones 
públicas para este perfil de edad, la educación, las experiencias personales son en general también muy negativas sobre los últimos años, y marcan el tono del discurso de las mayorías centrales de los grupos. En general se comparte el diagnóstico de que "están haciendo una segregación increíble" (GD2) como resultado de la subida generalizada de los precios públicos y se asume una creciente privatización de la educación, ya que en algunos casos las enseñanzas privadas resultan casi competitivas en precio con la enseñanza pública. Los más jóvenes (por ejemplo de nuestro GD1) también describen los efectos perversos de los mecanismos de selección temprana que se han introducido en la educación secundaria.

Y, finalmente, otra cuestión que se convierte en central en los grupos donde había participantes con hijos a cargo, es el tema de las ayudas a la maternidad. Tampoco hay en este caso intervenciones positivas sobre el acceso a ayudas públicas, aunque también está muy influido por la singularidad de los cheques guardería que funcionan en la Comunidad de Madrid. Pero más allá de las ayudas concretas, resulta en cualquier caso significativo que aparecen discursos muy críticos con las ideas en defensa de la inserción profesional de la mujer, y que se abra un espacio (que pese a no alimentar la dinámica de las reuniones tampoco es criticado en ellas) para la defensa de una realización al margen del trabajo asalariado:

“- M: Porque es que nos han dicho que es que trabajar, al trabajar nos sentimos muy realizadas, pero cuidando nuestros hijos y educándoles no. $\mathrm{Y}$ esa es la moto que nos han vendido." (GD3)

Este planteamiento surge entre la fracción más politizada de nuestra GD3, y aunque no genere un discurso grupal sí recibe el apoyo de los participantes masculinos en el grupo, y abre el espacio para una crítica a la agudización de la dependencia económica que sufren muchas madres. Esta misma fracción del grupo defiende en este contexto una renta específica de apoyo a la crianza, y denuncia que los ninis (criticados en varios grupos de 2011) son el producto de la imposibilidad de las madres para construir adecuadamente un entorno de socialización para sus hijos: "Pero es que luego la gente se les llena la boca de decir "estos ninis", no, perdona, eso es culpa de todos nosotros" (GD3). En cualquier caso, en este ámbito domina también la idea de que la crisis ha servido de excusa para una generalización de los recortes que han paralizado la tendencia hacia una mayor igualdad entre hombres y mujeres:

“- M: Yo creo que sí se han conseguido muchas cosas, ¿no? pero que se ha como paralizado o se ha vuelto a ir para atrás, una vez empezó la crisis, ¿no? que fue como «iUy! ¡Qué excusa más buena, la crisis, vamos a paralizar los derechos! ¡Que no sigan aumentando y sigan siendo de calidad!»” (GD3)

Cuando el vivir al día y el "menudeo" dejan de ser una etapa y se ven como una condición social, algunas fracciones de los grupos manejan una sensación de pérdida, pero dentro de un discurso ambiguo. Por una parte, en un discurso 
propio de la juventud, se ridiculiza un pasado tal vez demasiado pobre o simple (la pareja tradicional, con casa en propiedad, etc.) dentro de un mundo de inestabilidad y de cambio, cuyos nuevos parámetros ya han sido plenamente internalizados por las generaciones que componen los participantes en nuestros grupos. Sin embargo, ese pasado «convencional» es simultáneamente idílico e inalcanzable:

- M: Y que al final los momentos..., o sea, en la historia, o culturales también influyen, ¿no?, que igual antes estaba mucho más el modelo de vida feliz, casa..., y todavía está, ¿no?, en plan "la pareja de toda la vida, chalé, piscina y perro, ¿no? Y un poco..., y coche, y trabajo fijo”, ¿no? Y cómo ese modelo, y creo que esas cosas, están cambiando. [...]

- H: Para mí la cultura impuesta que viene es una cultura mucho más cortoplacista (- H: Sí), es la que nos viene..., nos viene ahora...

- M: Sí, de "préstamos, compras, tal..., ahora mismo...: lo tienes".

- H: Claro, y..., lo que habéis dicho, vivir al día, y todo esto.“

$[\ldots]$

"Es que lo que nos han quitado es el concepto de estabilidad, o sea, que al final es que sales a la calle y dices, bueno, "mira, una casa", "prrrr, cualquiera se mete en eso". (GD4)

\section{5. ¿UNA NUEVA POLÍTICA PARA EL CAMBIO?}

Los grupos se celebraron en junio de 2015, un momento en el que la política estaba particularmente presente una vez que se acababan de celebrar las elecciones autonómicas y municipales el mes anterior y en ese momento se acababan de investir nuevos gobiernos basados en el pacto de diversos partidos y que habían permitido alcanzar el poder, en algunos casos, a candidaturas ciudadanas identificadas con una nueva forma de hacer política a través nuevos partidos políticos y plataformas ciudadanas como Podemos, Ganemos, Guanyem, etc ${ }^{8}$. En este sentido, era prácticamente inevitable que se les preguntase por la posibilidad de que los cambios en la situación política pudieran influir en su situación personal, en el sentido de una posible mejora. A pesar de ello, la emergencia de esta nueva política fue planteada al final de las dinámicas, y salvo en el perfil del grupo GD3 no se introdujo como criterio la inclusión de uno o varios participantes vinculados a algún tipo de participación política. Por ello, tan sólo podemos destacar aquellos aspectos más significativos que emergieron en aquellos grupos donde esta cuestión generó un cierto debate (GD3, GD4 y GD1).

${ }^{8}$ No podemos entrar en este artículo a analizar los fundamentos teóricos, históricos y sociales de lo que podemos denominar como "nueva política" y que aquí tomamos fundamentalmente como significante discursivo, para este estudio fundamentado (crisis de representación, nuevos espacios comunes, ciudadanías alternativas, innovación social en la ciudad, etc.) pueden verse como ejemplo los imprescindibles trabajos de Joan Subirats (2011 y 2015). 
Una de las cuestiones más destacadas en varios grupos era el hecho de que se plantearan la llegada de esa nueva política ${ }^{9}$, en primer lugar, con un principio de realismo sobre lo que se puede esperar y no se puede esperar, con comentarios como que no se podía pedir magia ni pensar que todo iba a cambiar de un plumazo. Por ejemplo, en la dinámica de GD3 no existía un discurso claro en relación a Ahora Madrid y la alcaldesa Manuela Carmena, y sobre lo que podría cambiar en Madrid. En general, no había especial ilusión con el nuevo equipo de gobierno del ayuntamiento. Paradójicamente sí existía un cierto optimismo con las nuevas formas de participación y las posibilidades que abren para el cambio político, aunque se reconocía que esta nueva conciencia política se había activado ante una situación de máxima necesidad:

"Estamos así porque estamos en un momento que nos está afectando a nosotros, si no, ya se podía estar muriendo el mundo que si nosotros estamos bien, ponemos la musiquita y ya está." (GD3)

Una singularidad a señalar es que en el grupo donde (por el perfil de los contactados) había existido alguna experiencia de participación, ya no se percibía ni se relataba al resto como algo excepcional y más bien frustrante, sino como algo generalizable, pese a que la mayoría central de algunos grupos siguiera siendo relativamente indiferente con respecto a las llamadas a la concienciación que las fracciones más implicadas lanzaban al grupo. En otros grupos con presencia de más militantes, como el GD4, el discurso más tecnócrata del sometimiento a las autoridades exteriores de la UE, el FMI, etc. es contestado por parte de otros participantes, que defienden además que pequeños cambios pueden contribuir a un gran cambio. Pese a ello, el discurso escéptico es persistente, como muestra esta conversación:

“- H: Además, hay una cosa, que a veces perdemos el foco, pero la Unión Europea no es Dios. Nosotros también somos Unión Europea. Nosotros elegimos un gobierno, nosotros elegimos un gobierno, y ese gobierno también va a la Unión Europea a negociar.

- M: Sí, pero..., pero no. ¿Sabes?, yo siento que nosotros simplemente somos los mandados. Yo considero a la Unión Europea..., yo a la Unión Europea los veo como a una familia, y nosotros somos como los niños de esa familia, ¿sabes? Está el papá, la mamá, los niños, y tal, el perro, ¿sabes? (SE RÍE). Yo creo que somos los niños, no llegamos el perro, pero (...)” (GD4)

${ }^{9}$ El tema de las condiciones-simbólicas para la aparición de la llamada nueva política se aborda en los ya citados Alonso, Fernández Rodríguez e Ibáñez Rojo (2016a y 2016b).El contexto de la nueva política derivado de la idea de una acción juvenil contrahegemónica, cristalizado en el conjunto de movimientos que acabaron precipitando en el 15-M y que luego tenderían a ser generalizado en el campo de la política general española, ya se encontraba teorizado tempranamente por alguno de los más eximios representantes de esta llamada nueva política, como por ejemplo Errejón (2011a y 2011b, 2015). Desde el punto de vista de la sociología política y el análisis de la situación de las desventajas juveniles, en Benedicto y Morán (2014) donde se analizan los fundamentos del proceso que aquí recogemos. Asimismo, desde un punto de vista de la teoría de la acción colectiva y los nuevos movimientos sociales, se recomienda consultar la genealogía de Prieto Serrano, Betancor y Giménez Barroso (2016). 
Asimismo, se hacen múltiples referencias, presentes en otros grupos también, a una frivolización de la política, convertida en otro entretenimiento de la sociedad del espectáculo:

"o sea, que es que te ves un debate político y el..., éste, el..., Pedrerol, el de El chiringuito de jugones, y no sabes muy bien cuál es cuál, ¿sabes? Como que se ha creado, así, una (i), la gente $(i)$, muchas veces: "participa no sé quién, no sé quién...", y van más no por el invitado, si no: "hostia, este le va a dar..., le va a dar caña al otro..." Es un poco..., un poco show, ¿no?, que se ha frivolizado... O sea, es verdad que, claro, lo voy a meter en prime time, un análisis político aquí (¿) nadie lo vería, ¿no?, quieren ver un poco de espectáculo. Pero es verdad que sea ha llevado un poco más a lo superficial, al titular y a frivolizar un poco con ello." (GD4)

Esta percepción del marujeo mediático con la nueva política está presente en todos los grupos, y se plantea con una cierta ambigüedad. Se reconoce que hay más actividad, más presencia cotidiana de la política, pero también la existencia de pura teatralidad y rentabilidad en el nuevo atractivo de la política:

“- Eso es importante, claro.

- ... una es el boom político que ha habido, que la gente aquí está mucho más activa, y otra cosa es el salseo...

- Claro.

- Porque, ahora mismo, tú te pones a ver un debate político, y eso es salseo. O sea, es pam...No, no es un debate... o sea, es un debate político, es desde ellos el debate político, pero luego hay un programa que es el...

- Marujeo.

- ... aunque sean políticos y tal y cual, pues tienes a los 2 o 3 tertulianos de turno que lo convierten en un...pues eso: en una caza de brujas, (...) te meto caña para que haya discusión, para tal y cual. Creo que es un poco de las 2 cosas, eh. O sea, han conseguido vender por eso, pero luego también (...) Pero es lo que da audiencia..." (GD1)

Pese a estas críticas a que se haya convertido en el "nuevo corazón" (GD5), la mayoría de los participantes reconoce que, en este momento concreto y en contraste con épocas recientes ya pasadas, es cada vez más difícil ser apolítico o permanecer al margen de los debates en torno a la política española:

“- M: Ahora es más complicado, creo, por lo menos en mi círculo lo veo, ahora es mucho más complicado encontrar a alguien que te diga que soy apolítico. A pesar de que creo que es una falacia, pero antes la carga estaba que..., que eres apolítico, ahora mismo, quien más y quien menos, explicita su posición política, de una manera o de otra. No dice: "voto a este, o voto a este", pero...

- M: Sí, pero te dice lo que no le gusta de aquél, o lo que no..., o lo que sí que le gusta lo que ha dicho no sé quién. Sí que es verdad que eso sí..., yo lo noto más también (- H1: Sí, lo del: "yo paso de la política” no se oye ya tanto). Sí, no, eso ya no es tanto, ya no es tan guay" (GD4). 
Eso sí, en todos se reconoce que la política se ha puesto de moda, que se habla mucho más de ello, y que se ve mucho más en la tele (aunque muchos reconocen que no la siguen y que sus medios de información son básicamente internet y las redes sociales). Y por mucho marujeo que sea, siempre será mejor que lo que había antes, porque ha servido para acercar la política a la gente, en algunos casos despertando conciencias:

"H: O sea, yo, si a mí hace, eso, cuatro o cinco años me dicen que ahora el prime time en la tele van a ser debates políticos, con toda su parte de espectáculo que tienen, y vale, que serán de más o menos calidad, pero, joe, sí que pienso que ha habido un recorrido y que..., y que por qué no vamos a seguir... (- H: Sí, eso es porque la gente está más interesada...). Por eso, o sea, que... Y que estemos aquí en un grupo de discusión sobre esto... (RISAS), bueno, a lo mejor, sí que (...). Bueno, volviendo, que..., que hay temas que antes, pues eso..., estaban invisibilizados, y ahora son visibles, y ahora nos planteamos cosas, y oye. (GD4)

\section{CONCLUSIONES}

En este trabajo nuestro objetivo ha sido simplemente el de presentar los resultados de un estudio cualitativo con grupos de discusión en torno a las experiencias de los jóvenes españoles en relación a la crisis (y su posible salida), además de conocer cómo perciben los cambios sociales, políticos y económicos que estaban teniendo lugar en ese momento, y qué papel asignaban al Estado del Bienestar en un contexto de recortes y políticas de austeridad. Los seis grupos de discusión, que replicaban la composición de otros celebrados cuatro años antes, se celebraron en la región de Madrid en junio y julio de 2015 con el fin de comprobar si se habían producido cambios discursivos de entidad respecto de los enunciados en aquel entonces, poco después de la eclosión del 15-M pero que curiosamente se situaban en una perspectiva un tanto indiferente a la protesta social, siendo la capacidad de consumir el marco de referencia de la inclusión social, aunque ya por esa época era evidente para los participantes la existencia de una creciente vulnerabilidad social ante la que se sentían amenazados, y que limitaba sus posibilidades de independencia y autonomía personal y económica.

Los resultados de la segunda fase de la investigación han mostrado efectivamente una serie de transformaciones relevantes. Hay un consenso prácticamente absoluto en torno a la reducción generalizada de los salarios y el empeoramiento radical de las condiciones de trabajo que ha tenido lugar a lo largo de la crisis, reconociendo participantes de algunos grupos que la situación ha llegado a un límite. No se perciben mejoras pese a los discursos gubernamentales en relación a la salida de la crisis y la mejora de la economía. Se asume que la presión a la baja de este último período ha conseguido reducir la capacidad de resistencia de los trabajadores. Se comparte además la percepción de que sólo la población en situación límite tiene acceso a las ayudas estatales. 
Al mismo tiempo, hay un reconocimiento de que el discurso del miedo, base sobre la que se ha desplegado la política de recortes, ha encontrado sus límites, y que se está produciendo una cierta reacción de la ciudadanía. Ello ha dado lugar a un creciente interés por la política que, pese a las críticas que recibe por su excesivo espectáculo y frivolidad, ha terminado por introducir esperanzas, aunque sean leves y ambivalentes, de cambio, dentro de una perspectiva muy crítica en relación a la gestión política y económica del país. En general, la comparación entre esos dos momentos arrojó unos resultados muy similares entre los discursos juveniles aquí estudiados y los de nuestra investigación paralela sobre colectivos más amplios (con grupos en el período 2010-2014), que habían pasado de asumir la fatalidad de la crisis a traducir su malestar en una suerte de nueva conciencia crítica en torno a la política (ver Alonso, Fernández Rodríguez e Ibáñez Rojo, 2016a y 2016b). Sin duda, esta es una tendencia relevante que seguramente captará la atención de los sociólogos a lo largo de los próximos años.

\section{BIBLIOGRAFÍA}

ALONSO, L. E. (2013): "La sociohermenéutica como programa de investigación en sociología”, Arbor, 761, pp.1-15

ALONSO, L. E. (2014): "El contexto sociopolítico de la crisis económica: límites institucionales y protesta social”, en García N. y Ruesga, S. (coords.), ¿Qué ha pasado con la economía española?, Ediciones Pirámide, Madrid, pp. 83-116.

ALONSO, L. E., FERNÁNDEZ RODRÍGUEZ, C. J., IBANEZZ ROJO, R. (2011): "Del consumismo a la culpabilidad: en torno a los efectos disciplinarios de la crisis económica", Política y Sociedad, 48 (2), pp. 353-379.

ALONSO, L. E., FERNÁNDEZ RODRÍGUEZ, C. J., IBÁÑEZ ROJO, R. (2012): “Las identidades de ocio y consumo de los jóvenes en la era postlaboral", en Tezanos, J. F. (Ed.), Los nuevos problemas sociales: Duodécimo Foro sobre tendencias sociales, pp. 453-479.

ALONSO, L. E., FERNÁNDEZ RODRÍGUEZ, C. J., IBÁÑEZ ROJO, R. (2014):

"Crisis y nuevos patrones de consumo: discursos sociales acerca del consumo ecológico en el ámbito de las grandes ciudades españolas", Empiria: revista de metodología de ciencias sociales, 29, pp. 13-38.

ALONSO, L. E., FERNÁNDEZ RODRÍGUEZ, C. J., IBÁÑEZ ROJO, R. (2016a):"Entre la austeridad y el malestar: discursos sobre consumo y crisis económica en España”, Revista Española de Investigaciones Sociológicas, 155, pp. 21-36.

ALONSO, L. E., FERNÁNDEZ RODRÍGUEZ, C. J., IBÁÑEZ ROJO, R. (2016b):“De la moral del sacrificio a la conciencia de la precariedad: un análisis cualitativo de los discursos sobre la evolución de la crisis en España”, Política y Sociedad, 53(2), pp. 353-379.

BELTRÁN, M. (2016): Dramaturgia y hermenéutica: para entender la realidad social, Madrid, CIS. 
BENEDICTO, J., MORÁN, M. (2014): “¿Otra clase de politización? Representaciones de la vida colectiva y procesos de implicación cívica de los jóvenes en situación de desventaja", Revista Internacional de Sociología, 72(2), pp. 429-452.

CHAVEL, L. (2006): Les classes moyennes à la dérive, París, Seuil.

CINGOLANI, P. (2015): La précarité, París, Presses Universitaires de France, $2^{\mathrm{a}}$. ed.

COLECTIVO IOE (2015): “¿Qué recuperación? Desplome del empleo juvenil y deterioro de las rentas salariales en la legislatura del PP (2011-2014)", en http:// barometrosocial.es/archivos/1241\#more-1241 (último acceso 14/06/2016).

CONDE GUTIÉRREZ DEL ÁLAMO, F. (2009): Análisis sociológico del sistema de discursos, Madrid, CIS.

CONDE GUTIÉRREZ DEL ÁLAMO, F. (2015): “Introducción al análisis sociológico del sistema de discursos", en García Ferrando, M., Alvira, F., Alonso, L. E., Escobar, M. (Eds.), El análisis de la realidad social. Métodos y técnicas de investigación social, Madrid, Alianza Editorial, 4ed., pp. 641-663.

COWEN, T. (2014): Se acabó la clase media, Barcelona, Antoni Bosch Editor.

DAMON, J. (2013): Les classes moyennes, París, Presses Universitaires de France.

ERREJÓN, I. (2011a): “Algo habrán hecho bien. Una juventud sin futuro pero con estilo", en VV.AA., Juventud Sin Futuro, Barcelona, Icaria, pp. 67-78.

ERREJÓN, I. (2011b): "El 15M como discurso contrahegemónico", en Encrucijadas. Revista crítica de Ciencias Sociales, 2, pp. 120-145.

ERREJÓN, I. (2015): "Vieja y nueva comunicación política", Empiria: revista de metodología de ciencias sociales, 32, pp. 193-210.

FERNÁNDEZ RODRÍGUEZ, C.J., IBÁÑEZ ROJO, R. (2015): "Nuevas formas de protesta en un contexto de redefinición de los derechos públicos", en Torres Albero, C. (Ed.), España 2015: Situación Social, Madrid, CIS, pp. 1149-1159.

FLICK, U. (2015): El diseño de Investigación Cualitativa, Madrid, Morata.

FUNDACIÓN FOESSA (2014): VII Informe sobre exclusión y desarrollo social en España, Madrid, Fundación FOESSA.

FAIRCLOUGH, N. (2003): Analysing Discourse, Londres, Routledge.

GAGGI, M., NARDUZZI, E. (2006): El fin de la clase media, Madrid, Lengua de Trapo. GUTIÉRREZ BRITO, J. (2008): Dinámica del grupo de discusión, Madrid, CIS.

HERNÁNDEZ, E. (2014): El fin de la clase media, Madrid, Clave Intelectual.

IBÁÑEZ, J. (2015): "Perspectivas de la investigación social: el diseño en las tres perspectivas", en García Ferrando, M., Alvira, F., Alonso, L. E., Escobar, M. (Eds.),El análisis de la realidad social. Métodos y técnicas de investigación social, Madrid, Alianza Editorial, 4ed., pp. 42-75.

ÍÑIGUEZ RUEDA, L. (2003): "El análisis del discurso en las ciencias sociales: variedades, tradiciones y práctica”, en Íñiguez Rueda, L. (Ed.), Análisis del Discurso. Manual para las Ciencias Sociales, Barcelona, Editorial UOC, pp. 83124.

JONES, O. (2012): Chavs. La demonización de la clase obrera, Madrid, Capitán Swing. MAURIN, E. (2009): La peur du déclassement, París, Seuil.

ORTÍ, A. (1986):"La apertura y el enfoque cualitativo o estructural: la entrevista abierta o semidirectiva y la discusión de grupo", en García Ferrando, M., Ibáñez, J., Alvira, F. (comps.), El análisis de la realidad social. Métodos y técnicas de investigación, Madrid, Alianza, pp. 171-203.

PÉREZ INFANTE, J. I (2015): "Las reformas laborales en la crisis económica", Economiaz: Revista Vasca de Economía, 87, pp. 246-281. 
PÉREZ INFANTE, J. I. (2016): "Mercado de trabajo y devaluación salarial", Alternativas Económicas, 32, pp.32-33.

PEUGNY, C. (2009): Le déclassement, París, Grasset.

PRIETO SERRANO, D., BETANCOR, G., GIMÉNEZ BARROSO, J. (2016): "Activismo social y juventud: el $15 \mathrm{M}$ como espacio de socialización política", comunicación presentada al XII Congreso Español de Sociología, FES, Gijón, juniojulio 2016.

SANTOS ORTEGA, J. A. (2003):“"«Jóvenes de larga duración»: biografías laborales de los jóvenes españoles en la era de la flexibilidad informacional”, Revista Española de Sociología, 3, pp. 87-97.

SERRANO PASCUAL, A. (1995): "Procesos paradójicos de construcción de la juventud en un contexto de crisis en el mercado de trabajo", Revista Española de Investigaciones Sociológicas, 71-72, pp.177-199.

STANDING, G. (2013): El precariado. Una nueva clase social, Barcelona, Pasado y Presente.

STANDING, G. (2014): Precariado. Una carta de derechos, Madrid, Capitán Swing.

TEJERINA, B. et al. (2013): Crisis y precariedad vital. Trabajo, prácticas sociales y modos de vida en Francia y España, Valencia, Tiranc lo Blanc.

SUBIRATS, J. (2011), Otra sociedad ¿otra política?, Barcelona, Icaria.

SUBIRATS, J. (2015), "Políticas urbanas e innovación social. Entre la coprodución y la nueva institucionalidad" en Subirats, J. y García Bernardos, A. (Eds.), Innovación social y políticas urbanas en España, Barcelona, Icaria, pp. 95-113. 